\title{
Development of a new HPLC method for in vitro and in vivo studies of haloperidol in solid lipid nanoparticles
}

\author{
Mohd Yasir ${ }^{1,2, ",}$ Udai Vir Singh Sara ${ }^{3}$, Iti Som ${ }^{2}$ \\ ${ }^{1}$ Department of Pharmacy, Uttarakhand Technical University, Dehradun, (Uttarakhand), India, ${ }^{2}$ Department of Pharmaceutics, \\ I.T.S College of Pharmacy, Delhi-Meerut Road, Murad Nagar, Ghaziabad (UP), India, ${ }^{3}$ Department of Pharmaceutics, \\ Dr. M. C. Saxena College of Pharmacy, Lucknow, (UP), India
}

\begin{abstract}
A simple and sensitive HPLC method was developed and validated for the quantification of haloperidol in solid lipid nanoparticles (SLNs). The developed method was used for detection of shelf life of haloperidol in SLNs. Calibration curve of haloperidol was also constructed in rat plasma using loratidine as internal standard. In vivo studies were performed on rats and concentration of haloperidol in brain and blood was measured for the determination of various pharmacokinetic and hence brain targeting parameters. Chromatogram separation was achieved using $\mathrm{C} 18$ column as stationary phase. The mobile phase consisted of $100 \mathrm{mM} / \mathrm{L}$ potassium dihydrogen phosphate-acetonitrile-TEA (10:90:0.1, $v / v / v)$ and the $\mathrm{pH}$ was adjusted with $o$-phosphoric acid to 3.5. Flow rate of mobile phase was $2 \mathrm{~mL} / \mathrm{minute}$ and eluents were monitored at $230 \mathrm{~nm}$ using UV/VIS detector. The method was validated for linearity, precision, accuracy, reproducibility, limit of detection (LOD) and limit of quantification (LOQ). Linearity for haloperidol was in the range of $1-16 \mu \mathrm{g} / \mathrm{mL}$. The value of LOD and LOQ was found to be 0.045 and $0.135 \mu \mathrm{g} / \mathrm{mL}$ respectively. The shelf life of SLNs formulation was found to be 2.31 years at $4{ }^{\circ} \mathrm{C}$. Various parameters like drug targeting index (DTI), drug targeting efficiency (DTE) and nose-to-brain direct transport (DTP) were determined for HP-SLNs \& HP-Sol administered intranasally to evaluate the extent of nose-to-brain delivery. The value of DTI, DTE and DTP for HP-SLNs was found to be $23.62,2362.43 \%$ and $95.77 \%$ while for HP-Sol, values were $11.28,1128.61 \%$ and $91.14 \%$ respectively.
\end{abstract}

Uniterms: Haloperidol/quantification. Haloperidol/pharmacokinetic. Haloperidol/in vitro study. Haloperidol/in vivo study. High performance liquid chromatography/solid lipid nanoparticles. Plasma. Validation. Brain targeting.

\section{INTRODUCTION}

Haloperidol is an orally administered dopamine inverse agonist of the typical antipsychotic class of medication that chemically belongs to butyrophenone group (Gajski, Geri, Garaj-Vrhovac, 2014). Its mechanism of action is mediated by blockade of $\mathrm{D} 2$ dopamine receptors in brain (Benvegnú et al., 2011). Haloperidol is used to treat certain psychiatric conditions including schizophrenia, maniac states, medicament induced psychosis and neurological disorders with hyperkinesias (Forsman, 1976). Haloperidol is chemically 4-[4-(4-chlorophenyl)4-hydroxypiperidino] 4'- fluorobutyrophenone (Figure 1).

\footnotetext{
*Correspondence: M. Yasir. Department of Pharmaceutics. I.T.S College of Pharmacy. Delhi- Meerut Road, 201206 (UP), Murad Nagar, Ghaziabad, India. E- mail: mohdyasir31@gmail.com
}

The molecular formula of haloperidol is $\mathrm{C}_{21} \mathrm{H}_{23} \mathrm{ClFNO}_{2}$ and molecular weight is $375.86 \mathrm{~g} / \mathrm{mol}$.

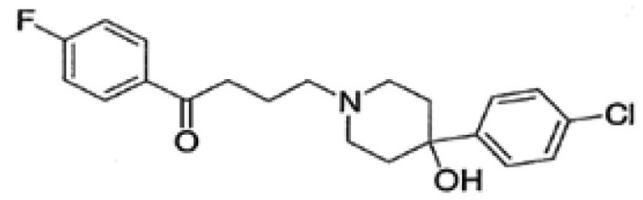

FIGURE 1 - Structure of haloperidol.

Various analytical techniques have been used for determination of haloperidol in pharmaceutical formulations. These include high performance liquid chromatography (HPLC) (Wate, Borkar, 2009), high performance thin-layer chromatography (HPTLC) (Sigrid et al., 2007), 19F NMR spectroscopy (Mojtaba et al., 2007), square-wave adsorptive stripping voltammetry 
at a mercury electrode (El-Desoky, Ghoneim, 2005), square-wave and cyclic voltammetry at hanging mercury drop electrode (Ribeiro et al., 2011), cyclic voltammetry at multi-walled carbon nanotubes-modified glassy carbon electrode (Huang et al., 2008). Non-aqueous titrimetric method has also been developed for haloperidol determination in pharmaceutical preparations (European Pharmacopoeia, 2002). UV spectrophotometric assay procedures have been developed and described in official compendia (Janicki, Ko, 1991; Chinese Pharmacopoeia, 2005; Yasir, Sara, 2014a). The analytical procedures like HPLC technique are still being frequently used and published.

The aim of present study was to develop and validate a new HPLC method for the quantitative analysis of haloperidol in SLNs. The different analytical performance parameters such as linearity, precision, accuracy, reproducibility, limit of detection (LOD) and limit of quantification (LOQ) were determined according to ICH Q2 (R1) guidelines (ICH, 2005; Dalila et al., 2012). For the determination of pharmacokinetic and brain targeting parameters after intranasal administration of haloperidol loaded solid lipid nanoparticles (HP-SLNs) and plain drug solution (HP-Sol), the calibration curve of haloperidol in rat plasma was prepared by the reported RP-HPLC method (Jain et al., 2011).

\section{MATERIAL AND METHODS}

\section{Chemicals}

Haloperidol was received as a gift sample from Vamsi Labs Ltd Solapur, Maharashtra, India. Potassium dihydrogen phosphate was purchased from Qualigens fine chemicals, Mumbai, India. Sodium hydroxide was procured from Fisher scientific, Mumbai, India. Acetonitrile $(\mathrm{ACN})$, Triethylamine (TEA) and $o$-phosphoric acid were purchased from Sigma-Aldrich, New Delhi, India. All reagents were of HPLC grade. Milli-Q grade (Millipore, Molsheim, France) water was used to prepare solutions wherever required and it was filtered before use through a $0.22 \mu \mathrm{m}$ membrane filter.

\section{Instruments}

Bath sonicator (Multitech Pvt. Ltd., N. Delhi), Balance (AUX 220, Shimadzu Corporation, Kyoto, Japan), Magnetic stirrer (Remi Instruments Pvt. Ltd., Mumbai, India), pH meter (Hicon Scientific Instruments, Delhi, India), Centrifuge (Remi Instruments Pvt. Ltd., India), Micro pipettes (Labnet, USA), Vortex mixer
(S.M. Scientific instruments Pvt. Ltd, Delhi) were used for the study.

HPLC System: Jasco HPLC system was used with following specifications

Column: C-18 Cosmosil packed column (5 $\mathrm{C}_{18}$ - MS-II, $\left.250 \mathrm{~mm} \times 4.6 \mathrm{~mm} \times 5.0 \mu \mathrm{m}\right)$

Pump: Jasco PU- 2080 plus

Type of Pump: Isocratic type

Detector: UV/VIS detector (Jasco UV 2075 plus)

Software: Jasco Borwin version (1.5, LC-Net II/ADC system)

Injector: Syringe type manual injector

Injection Vol.: $20 \mu \mathrm{L}$

Other accessories for HPLC embodies HiMedia

Syringe-driven filters of $0.22 \mu \mathrm{m}$ pore size

\section{HPLC method}

Several methods have been developed for the determination of haloperidol in pharmaceutical preparation.

The concentration of haloperidol had been earlier determined by HPLC method using methanol-water $(63: 37, \mathrm{v} / \mathrm{v})$ containing $0.2 \mathrm{M}$ ammonium acetate as mobile phase and diphenylamine as internal standard (IS) (Miyazaki et al., 1981). The method used here was slightly modified in the terms of mobile phase. $100 \mathrm{mM} / \mathrm{L}$ potassium dihydrogen phosphate-acetonitrile-TEA $(10: 90: 0.1, v / v / v)$ was used as mobile phase and the $\mathrm{pH}$ was adjusted with $o$-phosphoric acid to 3.5. It was sonicated for 15 minutes and filtered through $0.22 \mu \mathrm{m}$ membrane filter. Flow rate of mobile phase was maintained at $2 \mathrm{~mL} /$ min and eluents were monitored at $230 \mathrm{~nm}$. The samples $(20 \mu \mathrm{L})$ were injected using manual type HPLC injector. All determinations were performed at ambient temperature for a run time of $5 \mathrm{~min}$.

\section{Preparation of calibration curve}

A stock solution of $1.0 \mathrm{mg} / \mathrm{mL}$ of haloperidol was prepared in mobile phase. An appropriate volume of stock solution was further diluted with mobile phase to obtain a standard solution having a final concentration $100 \mu \mathrm{g} /$ $\mathrm{mL}$. Different concentrations (1-16 $\mu \mathrm{g} / \mathrm{mL})$ were made for the preparation of calibration curve from the prepared standard solution. The prepared dilutions were injected serially $(20 \mu \mathrm{L})$ and area under peak was recorded for each dilution. The calibration curve was constructed by 
plotting the concentration of haloperidol on $\mathrm{X}$-axis and peak area on Y-axis.

\section{Method validation}

HPLC method for Haloperidol was validated as per the ICH guidelines Q2 (R1) for linearity, precision, accuracy, reproducibility, LOD and LOQ.

\section{Linearity}

The linearity of response for haloperidol was assessed in the range of $1-16 \mu \mathrm{g} / \mathrm{mL}$ for standard drug.

\section{Accuracy as recovery}

Accuracy was determined using standard addition method. The pre-analyzed samples were spiked with extra 50, 100 and $150 \%$ of the standard haloperidol and the mixtures were analyzed by the proposed method. The experiment was performed in triplicate. The \% recovery, $\%$ relative standard deviation (RSD), and standard error of mean (SEM) were calculated at each concentration level.

\section{Precision}

The precision was determined at two levels as per $\mathrm{ICH}, \mathrm{Q} 2$ (R1) guidelines i.e. repeatability and intermediate precision.

a. Repeatability: Repeatability of drug sample was determined as intraday variation. Three replicates for each of the three concentrations were analyzed three times a day. Hence a minimum of 9 determinations were performed covering the specified range for the procedure. The $\%$ relative standard deviation was calculated for area to obtain the intraday variation

b. Intermediate precision: It was determined by interday variation (for three different days) for the determination of haloperidol at three different concentration levels of 4,8 and $12 \mu \mathrm{g} / \mathrm{mL}$ in triplicate. The $\%$ relative standard deviation was calculated for area to obtain the interday variation.

\section{Reproducibility}

Reproducibility of the method was investigated by obtaining precision of the method in another laboratory using the different instrument and analyzed by another person. Both intraday \& interday precision were calculated at three different concentration levels of $4,8,12 \mu \mathrm{g} / \mathrm{mL}$.

\section{$\angle O D$ and $L O Q$ determination}

LOD and LOQ of the drug were calculated as per ICH Q2 (R1) guidelines (ICH, 2005) using the standard deviation method with the help of equations 1 and 2 respectively.

$$
\begin{aligned}
& \mathrm{LOD}=3.3 \times \sigma / \mathrm{S} \\
& \mathrm{LOQ}=10 \times \sigma / \mathrm{S}
\end{aligned}
$$

where $\sigma=$ standard deviation of the response; $S=$ slope of the regression line.

\section{Application of developed HPLC method for In vitro studies i.e. in determination of shelf life}

Haloperidol loaded solid lipid nanoparticles (HPSLNs) were prepared by modified solvent emulsificationdiffusion technique (Kumar et al., 2013) and optimised by Boxbehken design (Yasir, Sara, 2013). The shelf life of optimized HP-SLNs was determined by conventional method using Arrhenius equation. Optimized SLN formulations were kept at $25 \pm 2{ }^{\circ} \mathrm{C} ; 30 \pm 2{ }^{\circ} \mathrm{C}$ and $40 \pm$ $2{ }^{\circ} \mathrm{C}$ at ambient RH (Shakeel et al., 2007). Samples were withdrawn after specified time intervals $(0,30,90$, and 180 days) and the drug content was determined using HPLC. Amount of drug remaining was determined at each interval. Logarithm of percent drug remaining versus time (days) was plotted. The degradation rate constant ' $\mathrm{K}$ ' was determined from the slope of the lines at each elevated temperature using the following equation (3).

$$
\text { Slope }=\frac{-\mathrm{K}}{2.303}
$$

Arrhenius Plot was constructed between $\log \mathrm{K}$ and $1 / T$ to determine the shelf life of optimized SLNs. K value at $4{ }^{\circ} \mathrm{C}$ was determined using extrapolation method. The shelf life $\left(\mathrm{T}_{0.9}\right)$ at $4{ }^{\circ} \mathrm{C}$ was calculated with the help of following equation (4).

$$
\mathrm{T}_{0.9}=\frac{0.1052}{\mathrm{~K} 4}
$$

\section{HPLC method in rat plasma for in vivo studies}

For in vivo studies, the calibration curve of haloperidol in rat plasma was prepared by the reported RP-HPLC method (Jain et al., 2011).

\section{Preparation of stock solution}

A stock solution $(1.0 \mathrm{mg} / \mathrm{mL})$ of drug was prepared in mobile phase. Aliquots from stock solution were further diluted with mobile phase to yield a standard solution of drug having a final concentration of $1 \mu \mathrm{g} / \mathrm{mL}$. 
Different concentrations (20 -90 ng/mL) were made for the preparation of calibration curve from the final standard solution.

\section{Preparation of calibration curve for determination of haloperidol in rat plasma}

Calibration curve was prepared by adding known amount of haloperidol $(20,30,40,50,60,70,80$ and 90 $\mathrm{ng} / \mathrm{mL}$ ) to $1 \mathrm{ml}$ of blank plasma in test tube separately. An aliquot $(500 \mu \mathrm{L})$ of loratidine solution (internal standard, concentration $100 \mathrm{ng} / \mathrm{mL}$ ) was added in each test tube separately. Each test tube was vortexed by adding $5 \mathrm{~mL}$ isopropyl alcohol for $5 \mathrm{~min}$ on a vortex mixer (S.M. Scientific instruments Pvt. Ltd, Delhi) and then centrifuged at $4000 \mathrm{rpm}$ for $10 \mathrm{~min}$ until a clear organic layer was separated. Organic layer was evaporated to dryness at room temperature. Subsequently dried sample was reconstituted with $0.3 \mathrm{ml}$ mobile phase and evaluated by HPLC for the presence of haloperidol. The calibration curve was constructed between concentration of haloperidol (X-axis) and peak area ratio of haloperidol and loratidine (Y-axis).

\section{In vivo studies for the determination of pharmacokinetic and Brain targeting parameters}

Comparative in vivo studies were performed for both haloperidol solution (positive control) (HP-Sol) and HPloaded SLNs administered intranasally (i.n.) and HP-Sol (positive control) administered intravenously (i.v.).

\section{Animals for in vivo study}

In vivo studies were performed on male albino wistar rats (Adult/weighing 200-250 g). A protocol for animal studies was approved by Institutional animal ethical committee and project number was ITS/03/ IACE/2013. The animals were kept under standard laboratory conditions i.e. temperature of $22 \pm 3{ }^{\circ} \mathrm{C}$ and relative humidity of $30 \%-70 \%$. The animals were housed in polypropylene cages, ( 6 animals per cage) with free access to standard laboratory diet and water ad libitum.

\section{Calculation of dose for rats}

Dose for the rats was calculated taking into consideration ratio of surface area of a rat to that of a human being (Yasir, Sara, 2014b). Surface area ratio for a rat $(200 \mathrm{~g})$ to a human $(70 \mathrm{~kg})$ is 56 . Dose for $200 \mathrm{~g}$ rat can be calculated by following equation (5).

$$
56=\frac{\text { Dose for human }}{\mathrm{x}}
$$

where $\mathrm{x}$ is the dose of rat per $200 \mathrm{~g}$. The dose of haloperidol for human is $10 \mathrm{mg}$. Hence $\mathrm{x}=0.179 \mathrm{mg}$ per $200 \mathrm{~g}$ of rat i.e. $0.893 \mathrm{mg} / \mathrm{kg}$.

In vivo study

For in vivo study, Rats were divided in three different groups:

Group A, positive control for intravenous (i.v.) drug administration (HP-Sol);

Group B, positive control for intranasal (i.n.) drug administration (HP-Sol); and

Group C, intranasal (i.n.) formulation administration (HP-SLNs).

Each group was divided into 8 subgroups (containing 6 animals) on time basis as given below:

Subgroup 1: drug was administered at time 0 and sacrifice was done after $0.167 \mathrm{~h}$

Subgroup 2: drug was administered at time 0 and sacrifice was done after $0.5 \mathrm{~h}$

Subgroup 3: drug was administered at time 0 and sacrifice was done after $1 \mathrm{~h}$

Subgroup 4: drug was administered at time 0 and sacrifice was done after $2 \mathrm{~h}$

Subgroup 5: drug was administered at time 0 and sacrifice was done after $4 \mathrm{~h}$

Subgroup 6: drug was administered at time 0 and sacrifice was done after $6 \mathrm{~h}$

Subgroup 7: drug was administered at time 0 and sacrifice was done after $8 \mathrm{~h}$

Subgroup 8: drug was administered at time 0 and sacrifice was done after $24 \mathrm{~h}$

\section{Procedure of drug administration}

Drug solution (positive control), containing $0.179 \mathrm{mg}$ (for rat weighing $200 \mathrm{~g}$ ) of haloperidol (equivalent to $0.89 \mathrm{mg} / \mathrm{kg}$ body weight), was injected through the tail vein $(10 \mu \mathrm{L})$ in one group of rats. Similarly, drug solution and drug formulation (HP-SLNs) containing $0.179 \mathrm{mg}$ of haloperidol were administered in each nostril in the other two groups with the help of micropipette $(10-100 \mu \mathrm{L})$ with $0.1 \mathrm{~mm}$ internal diameter at the delivery site. The rats were anaesthetized prior to nasal administration by pentobarbital sodium $(35-50 \mathrm{mg} / \mathrm{kg}$, i.p.) and held firmly from the back in a slanted position during nasal administration.

\section{Procedure for blood sampling}

The rats were killed humanely by overdose of pentobarbital sodium at different time intervals $(0.167,0.5$, $1,2,4,6,8$ and $24 \mathrm{~h}$ ) and the blood was collected using cardiac puncture in EDTA coated Eppendrof tubes. The 
blood was centrifuged at $4000 \mathrm{rpm}$ for $20 \mathrm{~min}$ and aliquots of the supernatant separated and stored at $-21{ }^{\circ} \mathrm{C}$ until drug analysis was carried out using HPLC (Kumar et al., 2008).

At the same interval of blood collection, the rats were sacrificed to separate the brain. Brain was rinsed twice with normal saline, made free from adhering tissue/ fluid and weighed. Cold normal saline solution was added (brain weight: normal saline, 1:5) to the brain and homogenized on ice. The homogenate was centrifuged at $4000 \mathrm{rpm}$ for $20 \mathrm{~min}$ at $4{ }^{\circ} \mathrm{C}$, and aliquots of the supernatant were separated and stored at $-21^{\circ} \mathrm{C}$ until drug analysis was carried out using HPLC (Haque et al., 2014).

\section{Procedure of drug extraction from plasma by liquid- liquid extraction method}

Chromatographic separation was achieved with a Cosmosil C18 column $(250 \mathrm{~mm} \times 4.6 \mathrm{~mm}$, particle size 5 $\mu \mathrm{m})$. The mobile phase consisted of $100 \mathrm{mmol} / \mathrm{L}$ potassium dihydrogen phosphate-acetonitrile-TEA(10:90:0.1, $v / v / v)$ and the $\mathrm{pH}$ was adjusted with $o$-phosphoric acid to 3.5 . The mobile phase was sonicated for $15 \mathrm{~min}$ and filtered through $0.22 \mu \mathrm{m}$ membrane filter before using. Flow rate of mobile phase was maintained at $2 \mathrm{~mL} / \mathrm{min}$ and eluents were monitored at $230 \mathrm{~nm}$. Twenty $\mu \mathrm{L}$ of sample was injected using a HPLC injector. All determinations were performed at ambient temperature for a run time of $5 \mathrm{~min}$.

The extraction of haloperidol from plasma and brain samples was carried out using the liquid-liquid extraction (LLE) technique. Plasma sample and homogenized brain tissue $(0.5 \mathrm{~mL})$ was mixed with $100 \mu \mathrm{L}$ loratidine $(100 \mathrm{ng} / \mathrm{mL})$ as internal standard solution (Jain et al., 2011; Rahman, Khatoon, Rahman, 2012). The mixture was shaken with $2 \mathrm{~mL}$ isopropyl alcohol for $2 \mathrm{~min}$ on a vortex mixer and then centrifuged at $4000 \mathrm{rpm}$ for $10 \mathrm{~min}$ until a clear organic layer was separated. Organic layer was evaporated to dryness under nitrogen gas at room temperature. Dried sample was then reconstituted with $0.3 \mathrm{~mL}$ mobile phase and evaluated by HPLC for the presence of drug.

\section{Analysis of pharmacokinetic and brain targeting parameters}

Plasma concentration-time profiles of haloperidol after i.n. and i.v. delivery were evaluated by pharmacokinetic software (PK Functions for Microsoft Excel, Pharsight Corporation, Mountain View, CA, USA). Various pharmacokinetic parameters as $C_{\max }, T_{\max }, \mathrm{AUC}_{0-}$ $\infty$ and elimination rate constant $(\mathrm{Ke})$ were calculated. Statistical analysis was performed using Graph pad prism 5.0 (Graph pad software San Diego, CA). All results were expressed as mean $\pm \mathrm{SD}$. Difference among the groups was compared with the analysis of variance (ANOVA) followed by Tukey-Kramer multiple comparison test. PValue $<0.05$ was considered statistically significant. The extent of nose-to-brain delivery could be evaluated by many parameters (Abdelbeary, Tadros, 2013):

(i) The brain/blood ratio, at $0.5 \mathrm{~h}$, following intranasal and intravenous administration (Vyas et al., 2005).

(ii) The relative bioavailability (RB) percentages following the intranasal administration in the blood and brain (MD et al., 2012).

(iii) The drug targeting index (DTI) (Wang, Jiang, Lu, 2003).

(iv) The drug targeting efficiency (DTE) percentage (Chow, Chen, Matsuura, 1999).

(v) The nose-to-brain direct transport percentage (DTP) (Zhang et al., 2004, Wang, Chi, Tang, 2008).

The relative bioavailability (\%) of the intranasal HP-SLNs formulation to intranasal HP-Sol was determined according to following equation (6).

$$
\mathrm{RB}(\%)=\frac{\left(\mathrm{AUC}_{\mathrm{HP}-\mathrm{SLN}(0-\infty)}\right) \mathrm{i} . \mathrm{n} .}{\left(\mathrm{AUC}_{\mathrm{HP}-\mathrm{Sol}(0-\infty)}\right) \mathrm{i} . \mathrm{n} .} \times 100
$$

The DTI can be described as the ratio of the AUC brain/AUC blood following i.n. administration to that following i.v. administration. Following equation (7) was used for the determination of DTI.

$$
\text { DTI }=\frac{(\text { AUC brain/AUC blood }) \text { i.n. }}{\text { (AUC brain/AUC blood }) \text { i.v. }}
$$

The percent brain targeting efficiency (DTE \%) and nose to brain direct transport percentage (DTP \%) were calculated with the help of given equation ( $8 \& 9$ ) (Wang, Jiang, Lu, 2003; Abdelbary, Tadros, 2013).

$$
\begin{gathered}
\operatorname{DTE}(\%)=\frac{\left(\mathrm{AUC}_{\text {brain }} / \mathrm{AUC}_{\text {blood }}\right)_{0-24, \text { i.n. }}}{\left(\mathrm{AUC}_{\text {brain }} / \mathrm{AUC}_{\text {blood }}\right)_{0-24, \text { i.v. }}} \times 100 \\
\operatorname{DTP~}(\%)=\frac{\left(\mathrm{AUC}_{0-24, \text { brain, i.n. }}-\mathrm{F}\right)}{\left(\mathrm{AUC}_{0-24, \text { brain, i.n. }}\right)} \times 100
\end{gathered}
$$

where $F=\left(\mathrm{AUC}_{0-24, \text { brain, i.v. }} / \mathrm{AUC}_{0-24, \text { blood, i.v. }}\right) \times \mathrm{AUC}_{0-24}$, blood, i.n., $\mathrm{AUC}_{0-24, \text { brain, i.n. }}$ is the area under the curve of brain following i.n. administration, $\mathrm{AUC}_{0-24 \text {, brain, i.v. }}$ is the area under the curve of brain following i.v. administration, $\mathrm{AUC}_{0-24 \text { blood, i.v. }}$ is the area under the curve of blood 
following i.v. administration, $\mathrm{AUC}_{0-24 \text { blood, i.n. }}$ is the area under the curve of blood following i.n. administration.

\section{RESULTS AND DISCUSSION}

\section{Preparation of calibration curve}

Calibration curve was constructed and a linear relationship was observed between peak area and concentration. The regression data for calibration curve showed a good linear relationship over concentration range of $1-16 \mu \mathrm{g} / \mathrm{mL}$ with respect to the peak area (Figure 2). The retention time of haloperidol was found to be $2.758 \pm 0.12 \mathrm{~min}$ as shown in Figure 3.

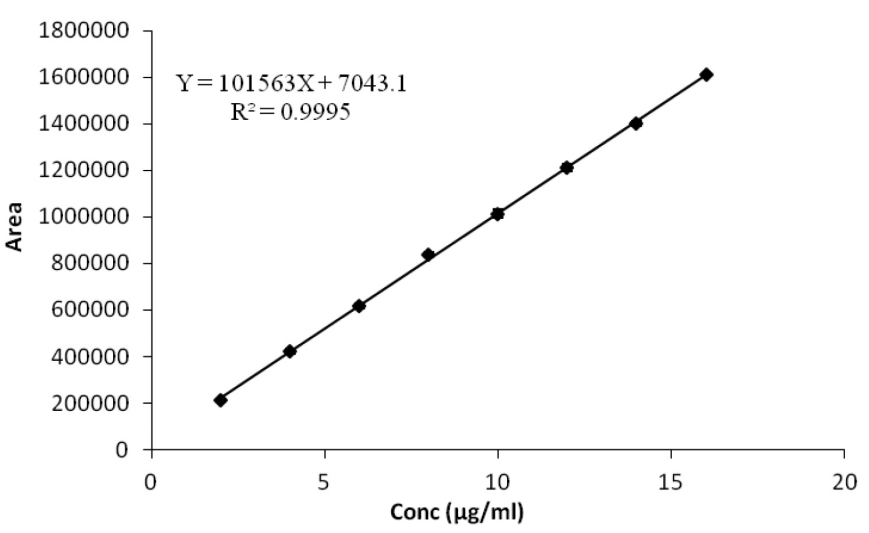

FIGURE 2 - Calibration curve of haloperidol by HPLC method.

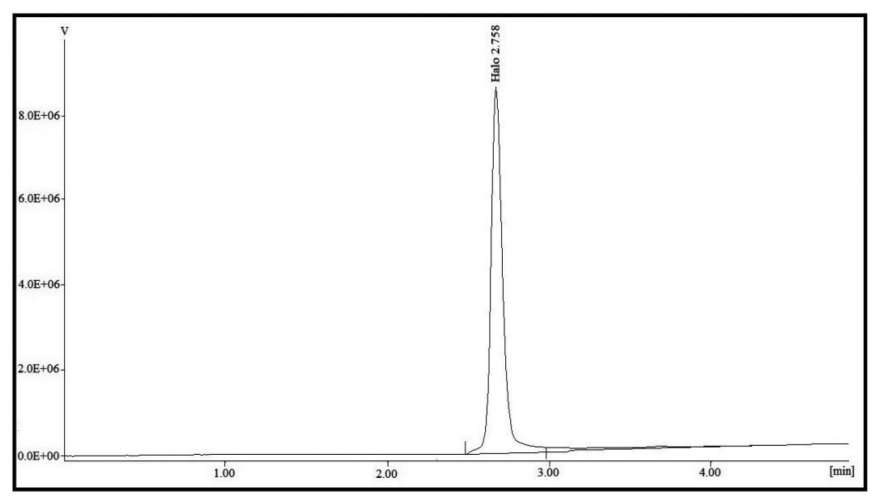

FIGURE 3 - HPLC chromatogram of haloperidol.

\section{Method validation}

Using the optimized chromatographic conditions, the developed HPLC method was validated with respect to linearity, precision, accuracy, reproducibility, LOD and LOQ as per the ICH guidelines.

\section{Linearity}

The linearity range of haloperidol solution was obtained as $1-16 \mu \mathrm{g} / \mathrm{mL}$. The linear regression equation was found to be $\mathrm{Y}=101563 \mathrm{X}+7043.1$ with correlation coefficient $\left(\mathrm{R}^{2}\right)$ of 0.9995 .

\section{Accuracy as recovery studies}

The proposed method afforded recovery of $99.55-$ $100.42 \%$ after spiking the additional standard drug solution to the previously analyzed test solution. The value of \% recovery, \% RSDs and SE are shown in Table I, which indicated the accuracy of the proposed method.

\section{Precision}

The precision was assessed by analyzing haloperidol in three different concentration levels as 4, 8 and $12 \mu \mathrm{g} /$ $\mathrm{ml}$ of in triplicate. The results of repeatability (intraday precision) and intermediate (interday) precision were expressed in the terms of \% RSD. The intraday and interday precision study of the developed method confirmed the adequate sample stability and method reliability where all RSDs were below $2 \%$ as shown in Table II.

\section{Reproducibility}

Reproducibility of the method was investigated by obtaining precision of the method in another laboratory using the different instrumentation and analysis being performed by another person. Both intraday \& interday precision were calculated and no significant differences were observed $(\mathrm{P}<0.05)$ in the \% RSD values of intraday and interday precision, which indicated the reproducibility of the method. The results of intraday and interday precision are shown in Table III.

\section{$\angle O D$ and $L O Q$ determination}

LOD and LOQ of this method were determined by the standard deviation method. The value of LOD and LOQ were found to be 0.045 and $0.135 \mu \mathrm{g} / \mathrm{ml}$ respectively, which signifies that proposed method can be used for the detection and quantification of haloperidol even in very low concentration.

\section{Application of Developed HPLC method for in vitro studies i.e. in determination of shelf life}

The percentage drug remaining in the optimized formulation (HP-SLNs) when stored for 180 days at elevated temperatures of $25 \pm 2{ }^{\circ} \mathrm{C} ; 30 \pm 2{ }^{\circ} \mathrm{C}$; and $40 \pm 2{ }^{\circ} \mathrm{C}$ at ambient RH was determined by HPLC method (Table IV). Figure 4a depicts the graph obtained by plotting Logarithm of percent drug remaining versus time (days). The degradation rate constant ' $\mathrm{K}$ ' was determined 
Development of a new HPLC method for in vitro and in vivo studies of haloperidol in solid lipid nanoparticles

TABLE I - Accuracy as recovery of proposed method

\begin{tabular}{ccccccc}
\hline \multirow{2}{*}{$\begin{array}{c}\text { \% of standard } \\
\text { spiked to the } \\
\text { sample }\end{array}$} & $\begin{array}{c}\text { Sample } \\
(\boldsymbol{\mu g} / \mathbf{m L})\end{array}$ & $\begin{array}{c}\text { Total including } \\
\text { spiked sample } \\
(\boldsymbol{\mu g} / \mathbf{m L})\end{array}$ & $\begin{array}{c}\text { Spiked sample } \\
\text { determined } \\
(\boldsymbol{\mu g} / \mathbf{m L}) \pm \mathbf{S D} \\
(\mathbf{n}=\mathbf{3})\end{array}$ & $\begin{array}{c}\text { \% drug } \\
\text { recovered }\end{array}$ & \% RSD & SE \\
\hline 50 & 10 & 15 & $15.03 \pm 0.29$ & 99.55 & 1.93 & 0.17 \\
100 & 10 & 20 & $19.97 \pm 0.21$ & 99.86 & 1.03 & 0.12 \\
150 & 10 & 25 & $25.11 \pm 0.35$ & 100.42 & 1.39 & 0.20 \\
\hline
\end{tabular}

TABLE II - Precision of proposed method

\begin{tabular}{cccccccc}
\hline $\begin{array}{c}\text { Conc. } \\
(\boldsymbol{\mu g} / \mathbf{m L})\end{array}$ & \begin{tabular}{c} 
Repeatability (intraday precision) \\
\cline { 2 - 8 } \\
\cline { 2 - 8 }$(\mathbf{n}=\mathbf{3})$
\end{tabular} & $\mathbf{S E M}$ & $\mathbf{\%} \mathbf{R S D}$ & Days & $\begin{array}{c}\text { Mean area } \pm \text { SD } \\
(\mathbf{n}=\mathbf{3})\end{array}$ & SEM & \% RSD \\
\hline 4 & $424842 \pm 2410$ & 1393 & 0.56 & 1 & $425363 \pm 3293$ & 1903 & 0.77 \\
& & & & 2 & $422999 \pm 5335$ & 3084 & 1.26 \\
& & & & 3 & $420934 \pm 3868$ & 2236 & 0.91 \\
\hline 8 & $835070 \pm 9054$ & 5234 & 1.08 & 1 & $840698 \pm 5981$ & 3457 & 0.71 \\
& & & & 2 & $839759 \pm 4031$ & 2330 & 0.48 \\
& & & & 3 & $836843 \pm 3414$ & 1973 & 0.41 \\
\hline 12 & $1256774 \pm 11926$ & 6894 & 0.95 & 1 & $1249711 \pm 12335$ & 7130 & 0.99 \\
& & & & 2 & $1251832 \pm 13451$ & 7775 & 1.1 \\
& & & & 3 & $1246394 \pm 13045$ & 7540 & 1.05 \\
\hline
\end{tabular}

TABLE III - Reproducibility of proposed method

\begin{tabular}{cccccccc}
\hline \multirow{2}{*}{$\begin{array}{c}\text { Conc. } \\
(\boldsymbol{\mu g} / \mathbf{m L})\end{array}$} & \begin{tabular}{c} 
Reaneatability (intraday precision) \\
\cline { 2 - 8 }$(\mathbf{n = 3})$
\end{tabular} & SEM & \% RSD & Days & $\begin{array}{c}\text { Mean area } \pm \text { SD } \\
(\mathbf{n}=\mathbf{3})\end{array}$ & SEM & \% RSD \\
\hline 4 & $421175 \pm 5048$ & 2918 & 1.19 & 1 & $424363 \pm 7371$ & 4261 & 1.74 \\
& & & & 2 & $417599 \pm 6567$ & 3796 & 1.57 \\
& & & & 3 & $425268 \pm 5608$ & 3241 & 1.32 \\
\hline 8 & $836737 \pm 11564$ & 6684 & 1.38 & 1 & $838365 \pm 10388$ & 6004 & 1.24 \\
& & & & 2 & $837659 \pm 8401$ & 4856 & 1.00 \\
& & & & 3 & $834843 \pm 12296$ & 7108 & 1.47 \\
\hline 12 & $1253774 \pm 14150$ & 8179 & 1.12 & 1 & $1250378 \pm 16891$ & 9763 & 1.35 \\
& & & & 2 & $1253832 \pm 11973$ & 6920 & 0.95 \\
& & & & 3 & $1248394 \pm 9806$ & 5668. & 0.79 \\
\hline
\end{tabular}

from the slope of the lines at each elevated temperature using the equation (3).

Arrhenius plot was constructed between $\log \mathrm{K}$ and 1/T (Table V and Figure 4b). From the plot, the value of degradation rate constant $(\mathrm{K} 4)$ at $4^{\circ} \mathrm{C}$ (refrigerator temperature) was determined. Shelf life was calculated by placing the value of $\mathrm{K} 4$ in equation (4). The shelf life of HP in SLNs at $4^{\circ} \mathrm{C}$ was found to be 2.31 years. The degradation kinetics of HP in SLNs was also determined and it was found to be first order kinetics as shown in Figure 4a. 
TABLE IV - Degradation of optimized HP- SLNs kept at $25 \pm 2{ }^{\circ} \mathrm{C} ; 30 \pm 2{ }^{\circ} \mathrm{C}$ and $40 \pm 2{ }^{\circ} \mathrm{C}$ at ambient RH

\begin{tabular}{cccc}
\hline Storage condition $\left({ }^{\circ} \mathbf{C}\right)$ & Sampling interval (days) & \% drug remaining & Log \% drug remaining \\
\hline $25 \pm 2$ & 0 & 100 & 2 \\
& 30 & 99.6 & 1.9983 \\
& 90 & 98.65 & 1.9942 \\
& 180 & 97.51 & 1.989 \\
\hline $30 \pm 2$ & 0 & 100 & 2 \\
& 30 & 99.26 & 1.9968 \\
& 90 & 98.23 & 1.9923 \\
& 180 & 97.13 & 1.9874 \\
\hline $40 \pm 2$ & 0 & 100 & 2 \\
& 30 & 99.01 & 1.9957 \\
& 90 & 97.66 & 1.9917 \\
& 180 & 96.49 & 1.9845 \\
\hline
\end{tabular}
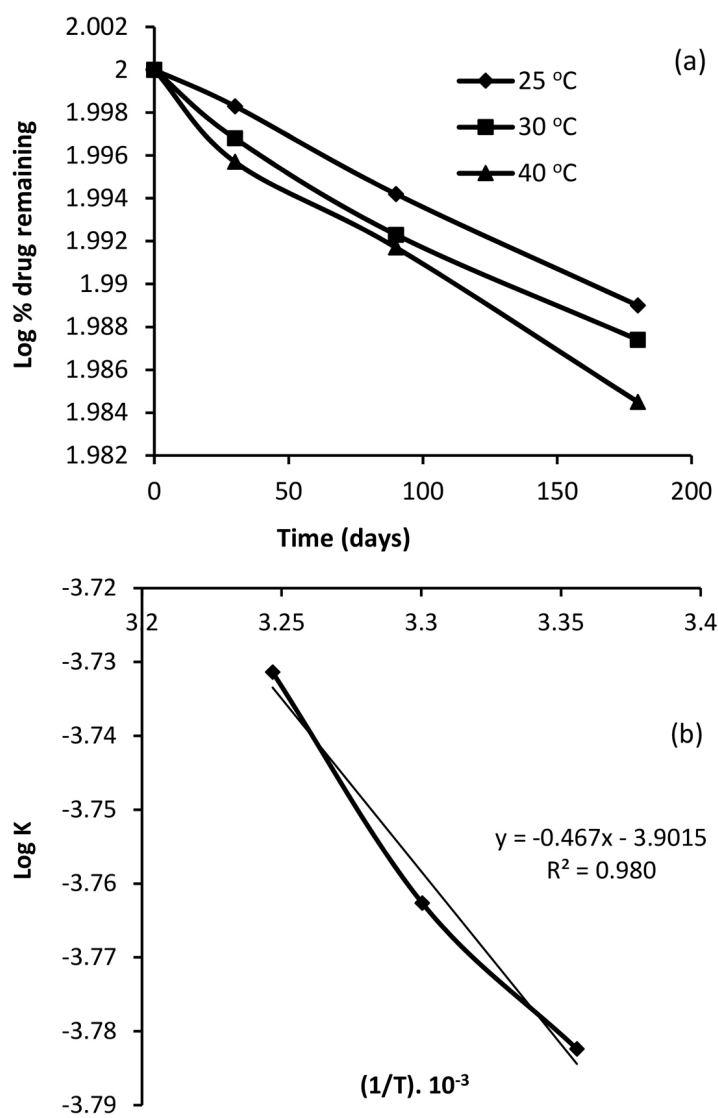

FIGURE 4 - (a) Log \% drug remaining vs. time plot (b) Arrhenius plot for optimized HP-SLNs formulation.

\section{HPLC method in rat plasma for in vivo studies}

For in vivo studies, the calibration curve of haloperidol in rat plasma was prepared by the reported RP-HPLC method (Jain et al., 2011).
Preparation of calibration curve for determination of haloperidol in rat plasma

Calibration curve was prepared in rat plasma by the reported RP-HPLC method (Jain et al., 2011). Calibration curve was obtained by plotting the peak area ratio of haloperidol to internal standard against the respective concentration (Figure 5). The linearity was observed in concentration range of $20-90 \mathrm{ng} / \mathrm{ml}$. The HPLC chromatogram of plasma spiked with haloperidol and blank plasma are shown in Figure 6a and 6b respectively. The approximate retention time of haloperidol and IS was found to be 2.536 and 3.59 min respectively.

\section{Drug extraction from plasma by liquid- liquid extraction method}

Liquid- liquid extraction method as described above was used for the drug extraction from rat plasma. Isopropyl alcohol was used as extraction solvent to obtain better recovery and good separation from the plasma impurities. The mobile phase was a mixture of $100 \mathrm{mM}$ potassium dihydrogen phosphate, acetonitrile and TEA (10:90:0.1, $v / v / v)$ and the $\mathrm{pH}$ was adjusted with $o$-phosphoric acid to 3.5. Loratidine was chosen as internal standard because it showed similar chromatographic behaviour to haloperidol with no interference. A satisfactory peak resolution and reasonable retention of the drug and internal standard were obtained.

\section{In vivo studies for the determination of pharmacokinetic \& brain targeting parameters}

The haloperidol concentrations in brain following 
TABLE V - Various parameters for calculation of shelf life

\begin{tabular}{cccccc}
\hline $\begin{array}{c}\text { Temperature } \\
\left({ }^{\circ} \mathbf{C}\right)\end{array}$ & $\begin{array}{c}\text { Temperature } \\
\left({ }^{\mathbf{0}} \mathbf{K}\right)\end{array}$ & $\begin{array}{c}(\mathbf{1} / \mathbf{T}) \times \mathbf{1 0}^{-3} \\
\left({ }^{\mathbf{0}} \mathbf{K}^{-\mathbf{1}}\right)\end{array}$ & Slope $\times \mathbf{1 0}^{-5}$ & $\mathbf{K} \times \mathbf{1 0}^{-4}$ & Log K \\
\hline 25 & 298 & 3.355704 & -7.1667 & 1.6505 & -3.78239 \\
30 & 303 & 3.30033 & -7.5 & 1.7273 & -3.76264 \\
40 & 308 & 3.246753 & -6.6667 & 1.5353 & -3.8138 \\
4 & 277 & 3.610183 & --- & 1.2496 & -3.9032 \\
\hline
\end{tabular}

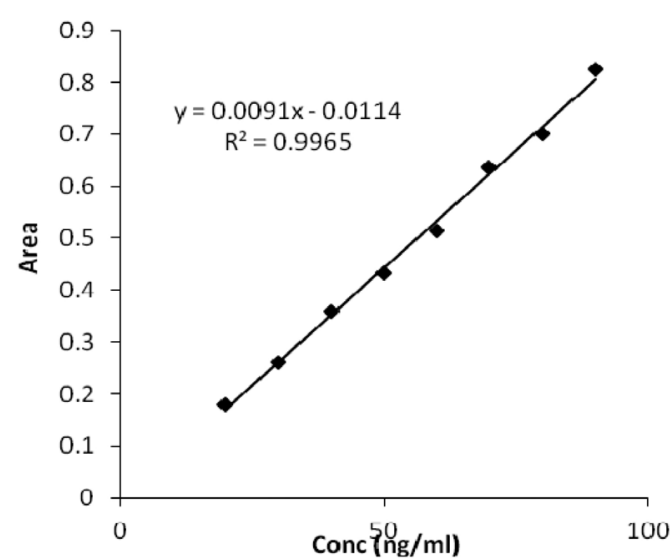

FIGURE 5 - Calibration curve of HP in rat plasma by HPLC method.

the i.n. administration of HP-SLNs were found to be significantly $(P<0.05)$ higher at all the time points as compared to both HP-Sol i.n. and HP-Sol i.v. (Figure 7a). The HP concentration in plasma following the i.n. of HP-SLNs were found to be significantly $(P<0.05)$ lower at all the time points compared to HP-Sol i.v. administration (Figure 7b). Various pharmacokinetic parameters of haloperidol were determined as shown in Table VI. The lower value of $T_{\max }$ for brain $(2 \mathrm{~h})$ as compared to blood $(4 \mathrm{~h})$ may attribute to the preferential nose to brain transport following i.n. administration. The value of Cmax (329.17 $\pm 20.89 \mathrm{ng} / \mathrm{mL})$ for brain after intranasal administration of HP-SLNs was significantly $(\mathrm{P}<0.05)$ higher than HP-Sol administered intranasally and intravenously. Similarly, the value of $\mathrm{AUC}_{0-\infty}(2389.17 \pm 78.82 \mathrm{ng} . \mathrm{h} / \mathrm{mL})$ of HP-SLNs i.n. was found to be significantly $(\mathrm{P}<0.05)$ higher than HP-Sol (i.n. and i.v.). This might be due to the direct transport of drug through olfactory route by bypassing the BBB.

As reported by Dhuria, Hanson and Frey (2010), the drug uptake by brain from the nasal mucosa can be achieved via three major pathways (i) a systemic pathway of drug absorption into the blood circulation which subsequently reaches to the brain across the
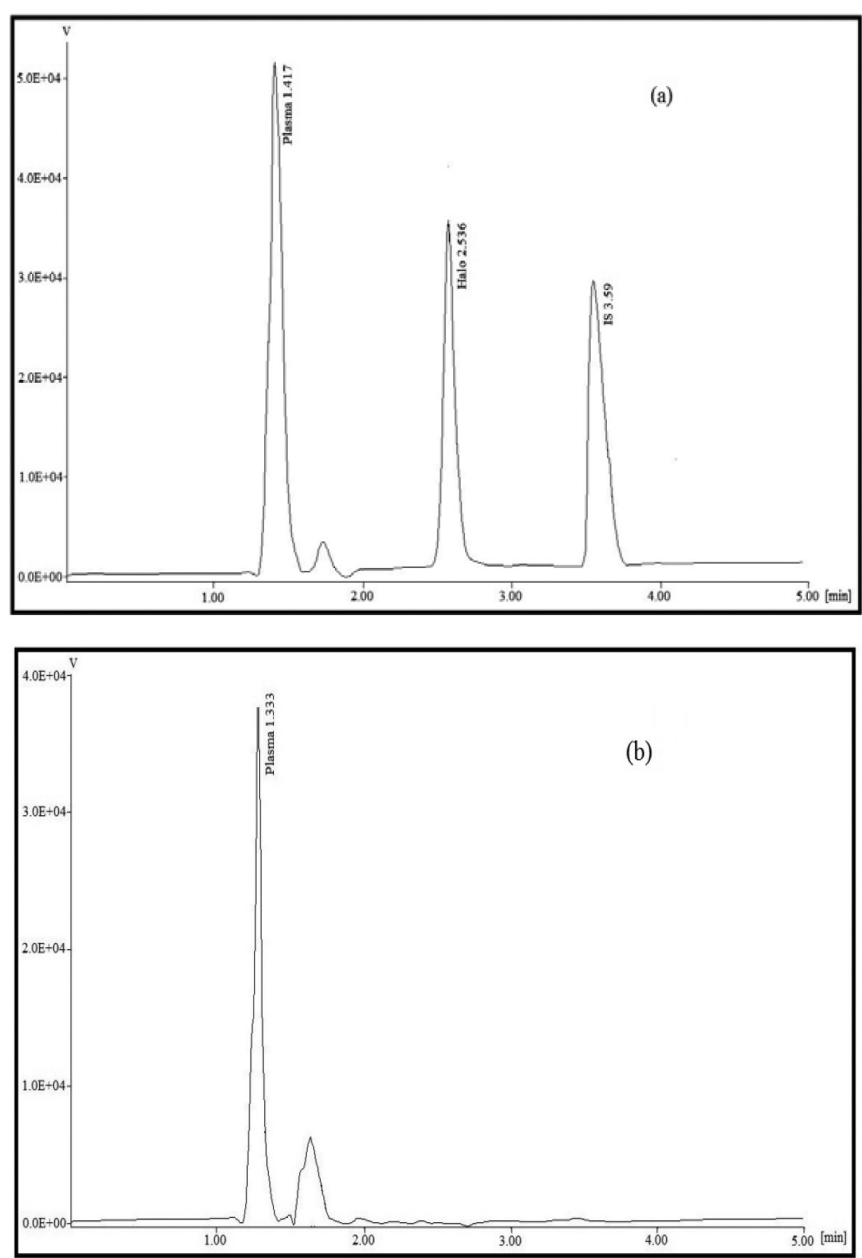

FIGURE 6 - HPLC chromatogram in (a) plasma spiked with drug and IS (b) blank plasma.

BBB, (ii) lymphatic pathway (Abdelbary, Tadros, 2013) (iii) a direct pathway from nasal mucosa epithelium into brain mainly along olfactory or trigeminal nerves by passing the BBB (MD et al., 2012). The extent of noseto-brain delivery could be evaluated by the following parameters.

a) The brain/blood ratio, at $0.5 \mathrm{~h}$, following intranasal and intravenous administration: This value was found to be $1.61,0.17$ and 0.03 for HP-SLNs i.n., HP-Sol i.n. and HP-Sol i.v. respectively (Table 
VII). A noteworthy high brain/blood ratio of HPSLNs could indicate the brain targeting potential of developed SLNs. The HP-Sol also reached directly in brain to some extent but significantly less than HP-SLNs and it could be due to lipophilic nature of haloperidol ( $\log \mathrm{p}$ approximately 4$)$. Similar findings were observed by Kumar et al. (2008).

b) Compared to HP-Sol administered intranasally, the percent relative bioavailability of intranasal HP-SLNs, were found to be $155.32 \pm 11.83$ and $349.72 \pm 26.13$ in blood and brain respectively (Table VI). The results revealed a significant $(\mathrm{P}<0.05)$ enhancement in the bioavailability of haloperidol in the brain following the intranasal administration of HPSLNs. These findings are in line with Abdelbary and Tadrosd (2013) who found that micellar nanocarriers increase the relatively bioavailability of olanzapine administered intranasally.

c) The DTI, DTE (\%) and DTP (\%) values were estimated to represent the percentage of drug directly transported to the brain via the olfactory or trigeminal pathway. The value of DTI, DTE \& DTP for HP-SLNs administered intranasally was found to be $23.62,2362.43 \% \& 95.77 \%$. While the value of DTI, DTE and DTP for HP-Sol administered intranasally was found to be $11.28,1128.61 \%$ and $91.14 \%$ respectively (Table VII). The DTI values $>1$ could confirm the direct pathway from nose to brain (Wang, Jiang, Lu, 2003). These findings are in line with Jain et al. (2010), Kanazawa et al. (2011) who found that micellar nanocarriers of zolmitriptan and coumarin increase the nose-to-brain uptake, via the olfactory region of the nasal cavity. Finally, the higher value of DTI, DTE (\%) and DTP (\%) suggested that HP-SLNs have better brain targeting potential as compared to HP-Sol administered intranasally. Similar findings have also been reported previously by Zhang et al. (2004).
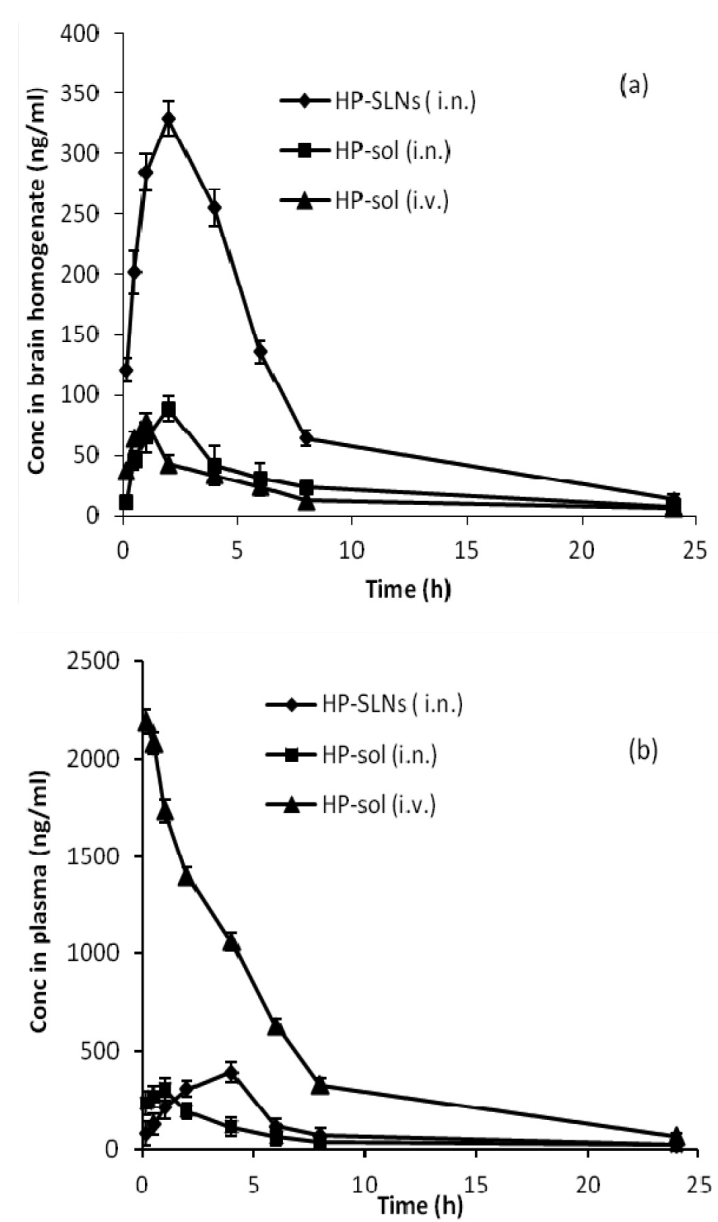

FIGURE 7 - Haloperidol concentration in (a) rat brain (b) rat plasma at different time intervals following HP-SLNs i.n., HP-Sol i.n. and HP-Sol i.v. administration.

\section{CONCLUSION}

A new and simple HPLC method for haloperidol was developed and validated over the concentration range from $1-16 \mu \mathrm{g} / \mathrm{mL}$. The method was successfully applied for the determination of haloperidol content in SLNs. Calibration curve was also prepared in rat plasma

TABLE VI - Pharmacokinetic parameters of haloperidol in brain and plasma

\begin{tabular}{|c|c|c|c|c|c|c|}
\hline \multirow{3}{*}{$\begin{array}{l}\text { P'kinetic } \\
\text { parameters }\end{array}$} & \multicolumn{6}{|c|}{ Type of formulation/route of administration } \\
\hline & \multicolumn{2}{|c|}{ HP-SLN i.n.* } & \multicolumn{2}{|c|}{ HP-Sol i.n. ${ }^{\#}$} & \multicolumn{2}{|c|}{ HP-Sol i.v. } \\
\hline & Brain & Plasma & Brain & Plasma & Brain & Plasma \\
\hline$T_{\max }(\mathrm{h})$ & 2 & 4 & 2 & 1 & 1 & 0.167 \\
\hline$K_{e}\left(h^{-1}\right)$ & $0.079 \pm 0.0065$ & $0.097 \pm 0.003$ & $0.077 \pm 0.005$ & $0.11 \pm 0.003$ & $0.095 \pm 0.003$ & $0.15 \pm 0.007$ \\
\hline $\mathrm{AUC}_{0-\infty}(\mathrm{ng} \cdot \mathrm{h} / \mathrm{mL})$ & $2389.17 \pm 78.82$ & $2612.31 \pm 40.67$ & $683.15 \pm 30.17$ & $1681.82 \pm 32.83$ & $500.82 \pm 12.78$ & $12017.5 \pm 180.87$ \\
\hline
\end{tabular}

Values are mean $\pm \mathrm{SD}, n=6 * P<0.05$ versus HP-Sol i.n., ${ }^{*} P<0.05$ versus HP-Sol i.v., ${ }^{\#} P<0.05$ versus HP-Sol i.v., $P<0.05$ results are significant 
Development of a new HPLC method for in vitro and in vivo studies of haloperidol in solid lipid nanoparticles

TABLE VII - Results of brain/blood ratio at 0.5 h, DTI, DTE (\%) and DTP (\%)

\begin{tabular}{lcccccc}
\hline $\begin{array}{l}\text { Formulation } \\
\text { and route of } \\
\text { administration }\end{array}$ & $\begin{array}{c}\text { Brain/blood } \\
\text { ratio at } \mathbf{0 . 5} \mathbf{~ h}\end{array}$ & DTI & DTE (\%) & DTP (\%) & Brain & Plasma \\
\hline HP- SLNs i.n. & 1.61 & 23.62 & 2362.43 & 95.77 & 349.72 & 155.32 \\
HP-Sol i.n. & 0.17 & 11.28 & 1128.61 & 91.14 & - & - \\
HP-Sol i.v. & 0.03 & - & - & - & - & - \\
\hline
\end{tabular}

${ }^{a}$ Bioavailability (\%) of HP-SLNs i.n. relative to HP-Sol i.n.

for determination of drug quantitatively. Satisfactory results were obtained, which signifies the reproducibility, sensitivity and reliability of method.

\section{ACKNOWLEDGEMENTS}

Authors are highly thankful to Management of I.T.S College of Pharmacy, Murad Nagar, Ghaziabad, India for providing research facilities. Authors gratefully acknowledge the name of Prof. S. Sadish Kumar (Principal, I.T.S College of Pharmacy, Murad Nagar, Ghaziabad, India) and Mr. D.S. Jolly (Administrator, I.T.S College of Pharmacy, Murad Nagar, Ghaziabad, India) for their co-operation during the preparation of this research article.

\section{CONFLICT OF INTEREST}

All authors have none to declare.

\section{LIST OF ABBREVIATIONS}

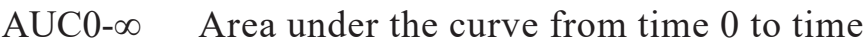
infinity

AUC0- $t \quad$ Area under the curve from time 0 to time $t$

BBB Blood brain barrier

Cmax Peak of maximum concentration

DTE Drug targeting efficiency

DTI Drug targeting index

DTP Direct transport percentage

HP Haloperidol

HP-SLNs Haloperidol loaded solid lipid nanoparticles

i.n. Intranasal

i.v. Intravenous

RB Relative bioavailability

SD Standard deviation

SLNs Solid lipid nanoparticles

\section{REFERENCES}

ABDELBARY, G.A.; TADROS, M.I. Brain targeting of olanzapine via intranasal delivery of core-shell difunctional block copolymer mixed nanomicellar carriers: In vitro characterization, ex vivo estimation of nasal toxicity and in vivo biodistribution studies. Int. J. Pharm., v.452, n.1, p.300-310, 2013.

BENVEGNÚ, D.M.; BARCELOS, R.C.; BOUFLEUR, N.; RECKZIEGEL, P.; PASE, C.S.; OURIQUE, A.F. Haloperidol-loaded polysorbate-coated polymeric nanocapsules increase its efficacy in the antipsychotic treatment in rats. Eur. J. Pharm. Biopharm., v.77, n.2, p.332-336, 2011.

CHINESE PHARMACOPOEIA. Chinese Pharmacopoeia Commission. Beijing: Chemical Industry Press, 2005. p.469.

CHOW, H.H.S.; CHEN, Z.; MATSUURA, G.T. Direct transport of cocaine from the nasal cavity to the brain following intranasal cocaine administration in rats. J. Pharm. Sci., v.88, n.8, p.754-758, 1999.

DALILA, M.B.; RAQUEL, C.S.B.; NARDELI, B.; CAMILA, S.P.; PATRÍCIA, R.; FERNANDA, C.F.; ALINE, F.O.; MAGALI, D.N.; CRISTIANE, B.S.; RUY, C.R.B.; MARILISE, E.B. Haloperidol-loaded polysorbate-coated polymeric nanocapsules decrease its adverse motor side effects and oxidative stress markers in rats. Neurochem. Int., v.61, n.5, p.623-631, 2012.

DHURIA, S.V.; HANSON, L.R.; FREY, W.H. Intranasal delivery to the central nervous system: mechanism and experimental considerations. J. Pharm. Sci., v.99, n.99, p.654-1673, 2010. 
EL-DESOKY, H.S.; GHONEIM, M.M. Assay of the antipsychotic drug haloperidol in bulk form, pharmaceutical formulation and biological fluids using square-wave adsorptive stripping voltammetry at a mercury electrode. $J$. Pharm. Biomed. Anal., v.38, n.3, p.543-550, 2005.

EUROPEAN PHARMACOPOEIA. Strasbourg: Council of Europe, 2002. p.1288-1289.

FORSMAN, A.O.; Individual variability in response to haloperidol. J. R. Soc. Med., v.69 n.1, p.9-13, 1976.

GAJSKI, G.; GERIĆ, M.; GARAJ-VRHOVAC, V. Evaluation of the in vitro cytogenotoxicity profile of antipsychotic drug haloperidol using human peripheral blood lymphocytes. Environ. Toxicol. Pharmacol., v.38, n.1, p.316-24, 2014.

HAQUE, S.; M.D., S.; SAHNI, J.K.; ALI, J.; BABOOTA, S. Development and evaluation of brain targeted intranasal alginate nanoparticles for treatment of depression. $J$. Psychiatr. Res., v.48, n.1, p.1-12, 2014.

HUANG, F.; PENG, Y.; JIN, G.; ZHANG, S.; KONG, J. Sensitive detection of haloperidol and hydroxyzine at multiwalled carbon nanotubes-modified glassy carbon electrodes. Sensors, v.8, n.3, p.1879-1889, 2008.

\section{INTERNATIONAL CONFERENCE ON HARMONIZATION.}

ICH. Harmonized Tripartite Guideline, validation of analytical procedures: text and methodology $Q 2$ (R1). Geneva: ICH, 2005.

JAIN, R.; NABAR, S.; DANDEKAR, P.; PATRAVALE, V. Micellar nanocarriers: potentialnose-to-brain delivery of zolmitriptan as novel migraine therapy. Pharm. Res., v.27, n.2, p.655-664, 2010.

JAIN, T.; BHANDARI, A.; RAM, V.; SHARMA, S.; CHAUDHARY, R.K.; PARAKH, M. High-performance liquid chromatographic method with diode array detection for quantification of haloperidol levels in schizophrenic patients during routine clinical practice. J. Bioanal. Biomed., v.3, n.1, p.8-12, 2011.

JANICKI, C.A.; KO, C.T. Haperidol. In: FLOREY, K. (ed.). Analytical profile of drug substances. New York: Academic Press, 1991. v.9. p.346-356.
KANAZAWA, T.; TAKI, H.; TANAKA, K.; TAKASHIMA, Y.; OKADA, H. Cell-penetratingpeptide-modified block copolymer micelles promote direct brain delivery via intranasal administration. Pharm. Res., v.28, n.9, p.2130$2139,2011$.

KUMAR, M.; MISRA, A.; BABBAR, A.K.; MISHRA, A.K.; MISHRA, P.; PATHAK, K. Intranasal nanoemulsion based brain targeting drug delivery system of risperidone. Int. J. Pharm., v.358, n.2, p.285-291, 2008.

KUMAR, R.; YASIR, M.; SARAF, S.A.; GAUR, P.K.; KUMAR. Y.; SINGH, A.P. Glyceryl monostearate based nanoparticles of mefenamic acid: Fabrication and in vitro characterization. Drug. Invent. Today., v.5, n.3, p.246-50, 2013.

MD, S.; KHAN, R.A.; MUSTAFA, G.; CHUTTANI, K.; BABOOTA, S.; SAHNI, J.K. Bromocriptine loaded chitosan nanoparticles intended for direct nose to brain delivery: pharmacodynamic, pharmacokinetic and scintigraphy study in mice model. Eur. J. Pharm. Sci., v.48, n.3, p.393-405, 2012.

MIYAZAKI, K.; ARITA, T.; OKA, I.; KOYAMA, T.; YAMASHITA, I. High performance liquid chromatographic determination of haloperidol in plasma. J. Chromatogr., v.223, n.1, p. 449-453, 1981.

MOJTABA, S.; LEILA, S.D.; ZAHRA, T.; SOHEILA, H. ${ }^{19} \mathrm{~F}$ NMR as a powerful technique for the assay of anti-psychotic drug haloperidol in human serum and pharmaceutical formulations. J. Pharm. Biomed. Anal., v.43, n.3, p.1116$1121,2007$.

RAHMAN, N.; KHATOON, A.; RAHMAN, H. Studies on the development of spectrophotometric method for the determination of haloperidol in pharmaceutical preparation. Quím. Nova., v.35, n.2, p.392-397, 2012.

RIBEIRO, F.W.P.; SOARES, J.E.S.; BECKER, H.; SOUZA, D.; LIMA-NETO, P.; CORREIA, A.N. Electrochemical mechanism and kinetics studies of haloperidol and its assay in commercial formulations. Electrochim. Acta., v.56, n.5, p.2036-2044, 2011.

SHAKEEL, F.; BABOOTA, S.; AHUJA, A.; ALI, J.; AQIL, M.; SHAFIQ, S. Nanoemulsions as vehicles for transdermal delivery of aceclofenac. APS PharmSciTech., v.8, n.4, p.191-199, 2007. 
SIGRID, M.; LORETO, P.; MARIO, V.; CARMEN, G.G.; MARTA, D.D. Quantitative determination of haloperidol in tablets by high performance thin-layer chromatography. J. Sep. Sci., v.30, n.5, p.772-777, 2007.

VYAS, T.K.; SHAHIWALA, A.; MARATHE, S.; MISRA, A. Intranasal drug delivery forbrain targeting. Curr. Drug Deliv., v.2, n.1, p.165-175, 2005.

WANG, F.; JIANG, X.; LU, W. Profiles of methotrexate in blood and CSF following intranasal and intravenous administration to rats. Int. J. Pharm., v.263, n.1, p.1-7, 2003.

WANG, X.; CHI, N.; TANG, X. Preparation of estradiol chitosan nanoparticles for improving nasal absorption and brain targeting. Eur. J. Pharm. Biopharm., v.70, n.3, p.735-740, 2008.

WATE, S.P.; BORKAR, A.A. RP-HPLC estimation of haloperidol and trihexyphenidyl in tablets. Int. J. Chem. Tech. Res., v.1, n.6, p.675-676, 2009.
YASIR, M.; SARA, U.V.S. Preparation and optimization of haloperidol loaded solid lipid nanoparticles by BoxBehnken design. J. Pharm. Res., v.7, n.3, p. 551-558, 2013.

YASIR, M.; SARA, U.V.S. Development and validation of UV spectrophotometric method for the estimation of haloperidol. British J. Pharm. Res., v.4, n.11, p.1407-1415, 2014a.

YASIR, M.; SARA, U.V.S. Solid lipid nanoparticles for nose to brain delivery of haloperidol: in vitro drug release and pharmacokinetics evaluation. Acta. Pharm. Sin. B., v.4, n.6, p. 454-463, 2014b.

ZHANG, Q.Z.; JIANG, X.G.; JIANG, W.M.; LU, W.; SU, L.N.; SHI, Z.Q. Preparation of nimodipine-loaded microemulsion for intranasal delivery and evaluation on the targetingefficiency to the brain. Int. J. Pharm., v.275, n.2, p.85-96, 2004.

Received for publication on $21^{\text {st }}$ March 2016 Accepted for publication on $04^{\text {th }}$ January 2017 